\title{
DEMAIS OU DE MENOS: OCLUSIVAS E NASAIS EM POSIÇÃO FINAL DE PALAVRA NA INTERLÍNGUA PORTUGUÊS BRASILEIRO - INGLÊS
}

\begin{abstract}
Resumo
Este artigo apresenta duas pesquisas recentes na área de aquisição da fonologia de inglês como L2 em relação às estratégias de simplificação silábica que os brasileiros utilizam para contornar estruturas estranhas às da sua L1. Por um lado, brasileiros podem apagar traços ou mesmo segmentos inteiros por conta da interferência da sua L1 no que concerne a produção das consoantes nasais do inglês $/ \mathrm{m} / \mathrm{e} / \mathrm{n} / \mathrm{em}$ posição de coda silábica. Por outro lado, há casos em que o aprendiz insere uma vogal epentética depois de consoantes oclusivas, também em coda silábica, para conformar a sílaba nos padrões da fonotaxe do português brasileiro. Ambas as estratégias podem causar problemas de inteligibilidade, já que no inglês, tanto os segmentos nasais (cam/can) como a presença da vogal (luck/lucky) têm papel contrastivo. Os resultados destas duas pesquisas apontam para uma visão gradiente do processo de aquisição de padrões fonotáticos do inglês por aprendizes brasileiros.
\end{abstract}

Palavras-chave: simplificação silábica, nasais, oclusivas, epêntese, fonotaxe

\begin{abstract}
This paper presents two recent studies developed in the field of acquisition of L2 phonology in relation to syllable modification strategies that Brazilian learners use in order to deal with structures different from those found in their L1. On the one hand, Brazilian learners may delete features or even segments due to L1 interference concerning the production of English nasal consonants $/ \mathrm{m} / \mathrm{and} / \mathrm{n} /$ in coda position. On the other hand, learners may insert an epenthetic vowel after stops in coda position so that the word is in accordance with Brazilian Portuguese phonotactics. Both strategies can cause intelligibility problems, considering the fact that in English nasal consonants in coda position such as in the pair cam/can, and the presence of the final vowel such as in luck/lucky, have a contrastive role. The results of these two studies indicate a gradient view of the acquisition of English phonotactis by Brazilian learners.
\end{abstract}

Keywords: syllable simplification, nasals, stops, epenthesis, phonotactics.

\section{Introdução}

A língua portuguesa, em relação à língua inglesa, apresenta menos possibilidades de codas, e os brasileiros, consequentemente, têm dificuldades em produzir corretamente consoantes nasais e oclusivas em final de palavra. Nenhum destes dois tipos de consoante ocorre 
fonologicamente em posição de final de palavra em português. O nível da estrutura silábica é aquele no qual muita interferência da primeira língua tem parecido ocorrer e, durante as últimas três décadas, numerosos estudos têm investigado estratégias usadas por falantes de diferentes L1 para dar conta de ataques e codas mais marcados do inglês (ver Eckman, 2004, para discussões teóricas e referências). Como já se sabe bem agora, aprendizes cuja L1 não permite uma determinada estrutura silábica se deparam com duas possibilidades a fim de simplificar a estrutura do inglês: eles podem reduzi-la, apagando um traço, parte de um segmento ou todo ele, ou podem expandi-la, adicionando uma vogal epentética para fazer com que a estrutura fique próxima dos padrões silábicos de sua L1. Ambas as estratégias estão em consonância com a preferência universal de sílabas sem coda (Bybee, 2001, p. 205). Este artigo descreve duas pesquisas recentes, que utilizaram análise acústica, e que ilustram o uso destes dois tipos principais de estratégias de simplificação usadas por aprendizes brasileiros de inglês.

\section{De menos : nasais em codas}

A língua portuguesa tem tanto vogais nasais como orais, as primeiras sendo geralmente consideradas reduções de uma vogal oral + uma consoante nasal (na maioria dos casos ainda aparecendo ortograficamente) como resultado da antecipação do gesto nasal (um processo de redução universalmente encontrado, de acordo com Bybee, 2001, p.201). A sequência vogal + "n" ou "m" é, portanto, realizada em português como uma vogal nasal, com a distinção neutralizada do ponto de articulação, em palavras como refém/reféns. É convencionado que em final de palavras apenas a bilabial " $m$ " ocorre ortograficamente, enquanto que no plural o " $\mathrm{m}$ " passa para a alveolar "n" antes da fricativa alveolar "s", não sendo este contraste mantido na pronúncia. Como resultado disso, aprendizes brasileiros parecem não se dar conta, ou tendem a esquecer, que o ponto de articulação de consoantes nasais em final de palavra é contrastivo em inglês, e geralmente apagam a consoante nasal, nasalizando a vogal (tal que as palavras team e teen tenham exatamente a mesma pronúncia), tendendo também a cometer erros de ortografia tais como botton, ou buttom quando querem dizer respectivamente bottom, ou button. O resultado é a perda do contraste na coda, principalmente na pronúncia, o que aumenta o trabalho do ouvinte ao requerer que ele adivinhe qual a nasal que se quis dizer pelo contexto, o que normalmente não é muito difícil, mas combinando-se com outras neutralizações típicas de brasileiros (tais como 
I/i, e æ/ع) e a falta de redução nas vogais de sílabas não tônicas, pode-se transformar num fator a mais para contribuir para a baixa inteligibilidade.

São poucos os estudos que relacionam as consoantes nasais na interlíngua de estudantes / falantes brasileiros de inglês. O estudo acústico de Monahan (2001, p. 23) aponta para o apagamento da consoante nasal e a nasalização da vogal precedente. Kluge (2004), em experimentos de produção e percepção (análises de outiva), chegou também a esta conclusão. Becker (2007) realizou análise acústica de consoantes nasais bilabiais e alveolares em codas de monossílabos, e seu estudo, além de definir um parâmetro acústico para a diferenciação de tais nasais, apresentou um estudo de freqüência em diferentes ambientes (vogal antecedente de duas qualidades distintas e silêncio após a nasal).

\subsection{Características Acústicas de Consoantes Nasais}

Fujimura (1962, p.1871), foi um dos precursores de estudos acústicos de consoantes nasais. Tais estudos se basearam no murmúrio de consoantes nasais. Deve-se esclarecer que o murmúrio nasal é o segmento acústico associado à radiação exclusivamente nasal da energia sonora, sendo um dos pontos, além das transições das vogais adjacentes, em que se estabelece o estudo espectral das nasais. Os resultados dos estudos de Fujimura nos deram uma das características espectrográficas diferenciadoras das consoantes nasais, isto é, mostraram que o anti-formante $^{1}$ (que espectralmente está associado a vales de energia) está localizado, para a nasal $/ \mathrm{m} /$, entre 750 e $1250 \mathrm{~Hz}$, e para /n/, entre 1450 e $2200 \mathrm{~Hz}$, sendo o ambiente vocálico em que se encontram as nasais o fator responsável pela ocorrência dos anti-formantes em uma ou outra extremidade desta faixa de freqüência. Porém, a própria literatura nos indica que os antiformantes são extremamente difíceis de localizar e medir.

Uma outra característica importante das consoantes nasais, além das faixas de freqüência de seus anti-formantes, é a existência de um chamado "formante nasal", que ocorre frequentemente na faixa de 200-300 Hz. Ainda uma ainda terceira característica para as consoantes nasais é que seus formantes tendem a ser altamente amortecidos, isto é, eles têm grandes larguras de banda, o que reflete uma rápida taxa de absorção da energia sonora. 


\subsection{Metodologia de Pesquisa}

Para o experimento de Becker (2007) foram gravadas as produções de dez pares de palavras (pares mínimos, com a diferença recaindo exatamente na nasal da coda), realizadas por dez adolescentes alunos de inglês de nível pré-intermediário, cinco meninos e cinco meninas. Todas as palavras eram monossilábicas, e as nasais da coda foram precedidas por duas vogais de qualidades distintas: [æ] e [I].

O grupo controle foi composto por dois adolescentes americanos, um menino e uma menina, que estavam morando no Brasil há menos de um ano na época das gravações, todas feitas em estúdio.

Foram gravadas três repetições de cada palavra do corpus para cada um dos informantes, totalizando 600 palavras para os alunos e 120 para o grupo controle. Os dados foram analisados utilizando o software PRAAT, um programa de análise acústica e síntese de fala, desenvolvido no Departamento de Fonética da Universidade de Amsterdã, Holanda (esse programa pode ser constantemente atualizado através de download: www.praat.org ). Foi utilizada a versão 4.4.30.

\subsection{Resultados}

Devido à falta, na literatura, de referências específicas sobre dados acústicos de nasais em codas, tanto de falantes nativos, como de alunos brasileiros de língua inglesa, procedeu-se à análise mais detalhada dos dados dos dois falantes nativos, tal que se pudesse, a partir daí, definir um ou mais parâmetros para a análise da produção dos brasileiros.

Depois da análise da duração relativa das nasais (obteve-se este valor relativo dividindose o valor médio da duração do murmúrio nasal, que nos dá a duração do segmento [m] ou [n], conforme o caso, pelo valor médio obtido com a duração da palavra alvo, e o resultado multiplicado por 100; o valor final nos diz qual é o percentual que o murmúrio nasal ocupa na duração total da palavra), e dos três primeiros formantes da vogal antecedente à nasal e dos três primeiros formantes da nasal (mais especificamente do murmúrio nasal) dos dados do grupo controle, os valores do segundo formante $(\mathrm{F} 2)$ da nasal (murmúrio nasal) se mostraram os mais consistentes. Para todas as palavras do corpus, nas três repetições de cada uma, e para ambos os informantes do grupo controle, os valores de F2 foram consistentemente superiores para a nasal 
[n] do que para a nasal [m] para um mesmo par. Este parâmetro foi, então, o utilizado para o fim de distinção entre estas duas nasais dentro dos limites desta pesquisa. Ladefoged já havia observado o fato de que, quando os lábios se fecham para [m], o segundo formante desta consoante, em especial, abaixa sua freqüência (Ladefoged, 2001, p.54), porém não mencionava comparativamente a produção de [n].

A comparação da produção dos alunos foi, então, baseada na análise dos pares mínimos: para um aluno ter realizado um som alveolar, sua produção deveria ter sido similar à produção de um falante nativo (os meninos foram comparados com o falante nativo, e as meninas com a falante nativa), isto é, o segundo formante do murmúrio nasal do segmento [n] deveria ter sido superior ao segundo formante do segmento nasal [m] para um mesmo par, e a diferença entre estes dois formantes deveria ter sido superior a $100 \mathrm{~Hz}$ para que se afirmasse que foi produzido um segmento [n], e não um [m]. Sons com F2 [n] superiores a F2 de [m], porém com diferença inferior a $100 \mathrm{~Hz}$ foram considerados acusticamente indistintos, e sons onde o F2 de [m] era superior ao F2 de [n], como produção oposta ao do grupo controle.

Os símbolos utilizados para as tabelas resumo mostradas a seguir são: "ل”" diferença entre $\mathrm{F} 2[\mathrm{n}]$ e F2[m] $\geq 100 \mathrm{~Hz}$. Portanto, a produção do aluno similar à produção do falante nativo com o qual foi comparado; "X" F2 de [m] $\geq$ F2 de [n]. Resultado oposto ao obtido com o falante nativo; "=" : F2 de [n] > F2 de [m], porém a diferença foi menor que $100 \mathrm{~Hz}$. Os percentuais (\%) correspondem aos valores percentuais de similaridade, igualdade ou oposição que ocorreram para cada um dos pares mínimos do experimento. Assim, por exemplo, o par CAMxCAN foi realizado pelas meninas em $60 \%$ dos casos de forma similar à falante nativa, $20 \%$ de forma oposta e $20 \%$ com indistinção acústica dos segmentos [m] e [n].

\begin{tabular}{|c|c|c|c|c|c|c|}
\hline & CAMxCAN & DAMxDAN & GRAMxGRAN & JAMxJAN & PAMxPAN & $\%$ FERAL \\
\hline$\% \sqrt{ }$ & 60 & 40 & 60 & 60 & 40 & 52 \\
\hline$\% \mathrm{X}$ & 20 & 0 & 20 & 0 & 0 & 8 \\
\hline$\%=$ & 20 & 60 & 20 & 40 & 60 & 40 \\
\hline
\end{tabular}

RESUMO DOS RESULTADOS - PARES [æ] - MENINAS 


\begin{tabular}{|c|c|c|c|c|c|c|}
\hline & CAMxCAN & DAMxDAN & GRAMxGRAN & JAMxJAN & PAMxPAN & $\% G E R A L$ \\
\hline$\% \sqrt{ }$ & 20 & 20 & 20 & 0 & 40 & 20 \\
\hline$\% \mathrm{X}$ & 40 & 0 & 40 & 40 & 20 & 28 \\
\hline$\%=$ & 40 & 80 & 40 & 60 & 40 & 52 \\
\hline
\end{tabular}

RESUMO DOS RESULTADOS - PARES [æ] - MENINOS

\begin{tabular}{|c|c|c|c|c|c|c|}
\hline & CAMxCAN & DAMxDAN & GRAMxGRAN & JAMxJAN & PAMxPAN & $\%$ GERAL \\
\hline$\% \sqrt{ }$ & 40 & 30 & 40 & 30 & 40 & 36 \\
\hline$\% \mathrm{X}$ & 30 & 0 & 30 & 20 & 10 & 18 \\
\hline$\%=$ & 30 & 70 & 30 & 50 & 50 & 46 \\
\hline
\end{tabular}

RESUMO - PERCENTUAL GERAL (MENINOS E MENINAS) DOS RESULTADOS [æ]

\begin{tabular}{|c|c|c|c|c|c|c|}
\hline & DIMxDIN & GYMxGIN & PIMxPIN & SKIMxSKIN & TIMxTIN & \%GERAL \\
\hline$\% \sqrt{ }$ & 80 & 60 & 60 & 40 & 40 & 56 \\
\hline$\% \mathrm{X}$ & 0 & 20 & 20 & 40 & 40 & 24 \\
\hline$\%=$ & 20 & 20 & 20 & 20 & 20 & 20 \\
\hline
\end{tabular}

RESUMO DOS RESULTADOS - PARES [I] - MENINAS

\begin{tabular}{|c|c|c|c|c|c|c|}
\hline & DIMxDIN & GYMxGIN & PIMxPIN & SKIMxSKIN & TIMxTIN & $\%$ GERAL \\
\hline$\% \sqrt{ }$ & 40 & 20 & 0 & 60 & 40 & 32 \\
\hline$\% \mathrm{X}$ & 60 & 20 & 60 & 40 & 60 & 48 \\
\hline$\%=$ & 0 & 60 & 40 & 0 & 0 & 20
\end{tabular}

RESUMO DOS RESULTADOS - PARES [I] - MENINOS

\begin{tabular}{|c|c|c|c|c|c|c|}
\hline & DIMxDIN & GYMxGIN & PIMxPIN & SKIMxSKIN & TIMxTIN & $\%$ GERAL \\
\hline$\% \sqrt{ }$ & 60 & 40 & 30 & 50 & 40 & 44 \\
\hline$\% \mathrm{X}$ & 30 & 20 & 40 & 40 & 50 & 36 \\
\hline$\%=$ & 10 & 40 & 30 & 10 & 10 & 20 \\
\hline
\end{tabular}

RESUMO - PERCENTUAL GERAL (MENINOS E MENINAS) DOS RESULTADOS [I] 
$\mathrm{O}$ percentual geral (incluindo produções dos meninos e das meninas) no quesito similaridade, portanto, foi de $36 \%$ para os pares [æ] e $44 \%$ para os pares [I] isto é, $40 \%$ de similaridade à produção de falantes nativos.

Assim, através de comparações feitas das produções dos alunos com a produção de dois falantes nativos, com base na análise acústica do segundo formante do murmúrio nasal (este foi o parâmetro acústico definido como padrão através da análise dos dados do grupo controle), verificou-se que $40 \%$ das palavras alvo produzidas pelos alunos era acusticamente similar à produção das nasais feita por um falante nativo (onde o F2 de [n] é maior que o F2 de [m]). Um terço das produções dos alunos mostra valores de F2 para [n] superiores aos [m], porém muito próximos entre si, o que talvez possa a vir a sinalizar duas possibilidades: num extremo, a tentativa de acerto, quando o aluno tenta realizar um ou outro segmento, mas não é plenamente bem sucedido, e no outro a possibilidade de que esteja nasalizando a vogal antecedente à nasal, daí a indistinção. Ainda do total, 27\% dos resultados traz valores de F2 do murmúrio nasal de [m] maiores que os de [n], o oposto do que ocorre com as produções de um falante nativo. A hipótese de que estudantes de inglês falantes nativos de português brasileiro tendem a produzir vogais nasalizadas pode, portanto, ser verdadeira para um terço dos casos, segundo os resultados obtidos neste trabalho, e nas condições delimitadas nesta pesquisa.

Com relação ao ambiente antecedente à nasal, os dados mostraram que com a vogal antecedente [I] a produção tende a ser, percentualmente, mais próxima à produção de falantes nativos: $56 \%$ de similaridade (contra 52\% para os pares [æ]) para as meninas, e $32 \%$ (contra $20 \%$ para os pares [æ]) para os meninos. As meninas conseguiram, no geral, um grau de similaridade com a falante nativa bem superior ao que os meninos conseguem com o falante nativo: $54 \%$ contra $26 \%$ dos meninos.

A título de ilustração, são abaixo apresentados espectrogramas para CAM x CAN produzidos pela falante nativa (B) e por uma das alunas brasileiras (BA): 


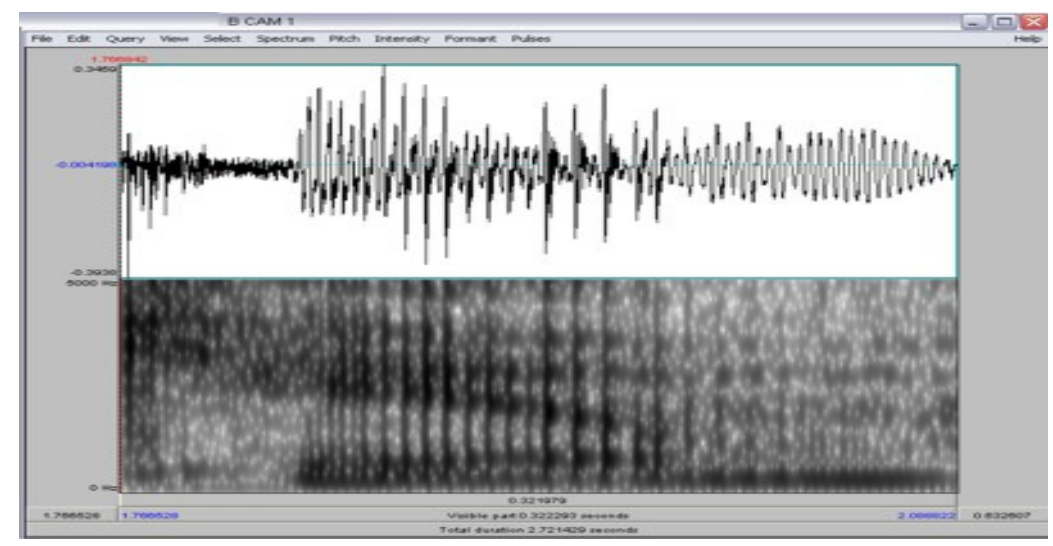

1. Falante Nativo (B) ( + ) - Palavra Alvo: CAM

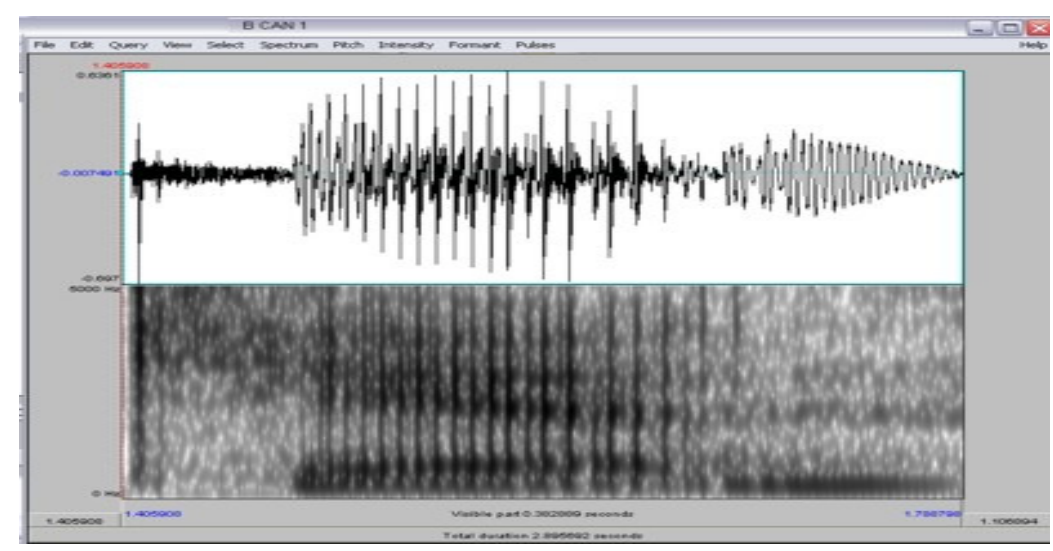

2. Falante Nativo (B) (ㅇ) - Palavra Alvo: CAN

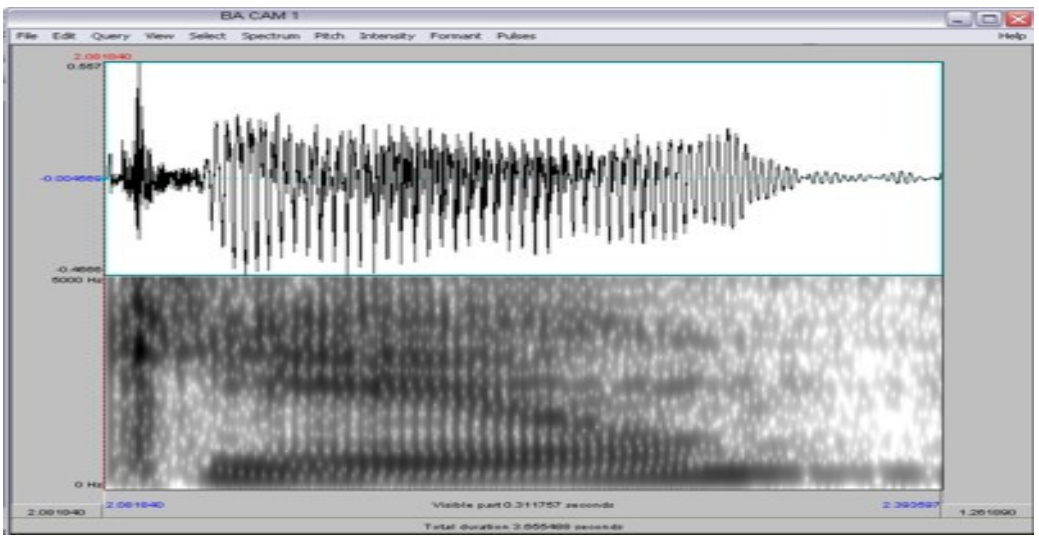

3. Informante Aluna (BA) () - Palavra Alvo: CAM Produção similar à de falante nativo 


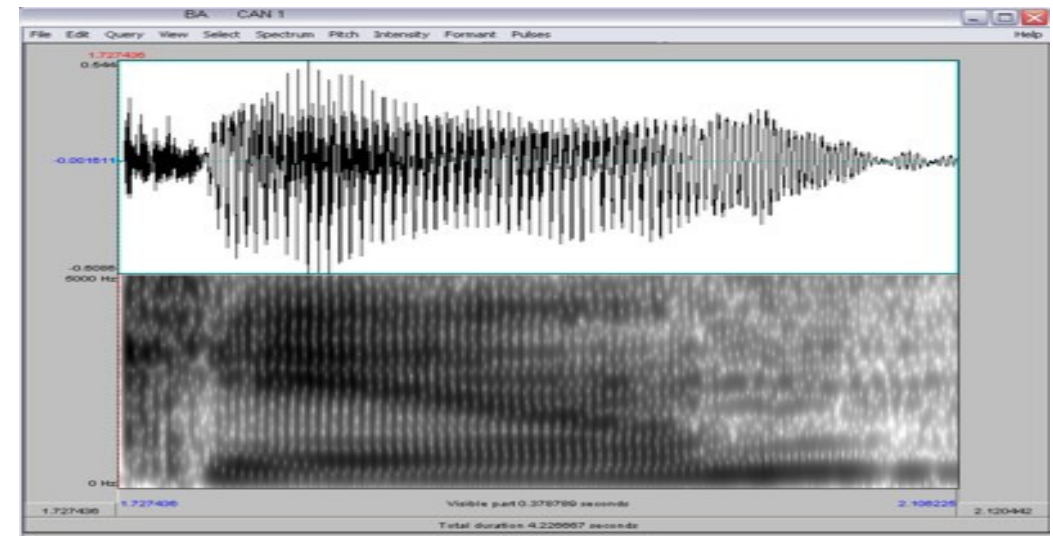

4. Informante Aluna (BA) ( $($ ) - Palavra Alvo: CAN Produção similar à de falante nativo

\section{Demais: oclusivas em codas}

Enquanto a estratégia usual para consoantes nasais em final de palavra é o seu apagamento e antecipação do gesto para o segmento vocálico precedente, falantes do português brasileiro não agem desta forma com as oclusivas, preferindo aumentar ao invés de reduzir a substância fonética. Isto resulta em formas tais como [bukI] para a palavra book, com a oclusiva da coda se transformando em ataque de uma segunda sílaba curta. Isto significa, entretanto, que há um risco de confusão entre palavras que têm uma vogal anterior final alta na suas formas lexicais como bookie. Existem muitos pares mínimos em potencial deste tipo, claramente distinguíveis em variedades padrão de inglês, porque a oclusiva final tende a ser glotalizada e então não há soltura de outros articuladores. Um bom número de estudos tentou estabelecer os ambientes nos quais a paragoge ocorre mais frequentemente (Major, 1986), enquanto Silveira (2004) investigou os efeitos de treinamento de pronúncia na redução de paragoge. Ferreira (2007), entretanto, baseou seu estudo na premissa que paragoge não é um fenômeno binário, mas gradiente, com mais ou menos material fonético seguindo a oclusiva final dependendo do estágio de conhecimento do aprendiz. Este foi o primeiro estudo neste campo a usar análise instrumental para medir a duração e o grau de vozeamento nas vogais epentéticas em final de palavra. 


\subsection{Oclusivas em coda silábica}

No que concerne a aquisição da fonologia da língua inglesa como L2, já era conhecida a dificuldade do aprendiz brasileiro em produzir consoantes oclusivas em posição de coda em final de palavra, pois tais segmentos não ocorrem nesta posição no português brasileiro. Estudos haviam mostrado que os aprendizes, principalmente em estágios iniciais de aquisição de L2, comumente acrescentavam um elemento vocálico após a produção da oclusiva - a epêntese para conformar a estrutura silábica da L2 no padrão do PB (Baptista \& Silva Filho (1997) e Koerich (2002)). Estes trabalhos, entre outros, utilizaram-se da analise de outiva para verificar se o aprendiz havia inserido a vogal epentética ou não. Já o estudo de Ferreira (2007) contou com o instrumento de análise acústica através de um programa de computador (Praat) que permitiu não somente constatar a presença ou ausência da vogal e suas características, mas também a ocorrência de eventos fonéticos produzidos pelos informantes. O objetivo maior desta investigação era o de contrastar a produção de vocábulos de sequência CVC e CVCV, como no par mínimo luck/lucky, e analisar quais eram as principais diferenças entre a vogal epentética de CVC (quando houvesse) e a vogal final de CVCV. No presente artigo, concentraremos as atenções nas realizações da vogal epentética e em outros eventos fonéticos que sucederam a oclusiva final em CVC. Dentre outras descobertas da pesquisa, foi possível perceber que as características do elemento vocálico após a oclusiva final podem variar bastante, principalmente em termos de duração e vozeamento. Além disso, há casos em que o aprendiz não insere um elemento vocálico, mas produz algum outro evento fonético (africação, palatalização ou aspiração), sinalizando que o processo de aquisição das oclusivas em posição de coda em final de palavra ainda não foi concluído.

\subsection{Metodologia}

Para esta pesquisa, foram gravados doze informantes brasileiros - seis do sexo feminino e seis do masculino - e uma falante nativa. Os brasileiros tinham entre 13 e 17 anos de idade, eram alunos de uma instituição privada de ensino de línguas, e tinham nível intermediário de proficiência na língua (250-300 horas de instrução). A falante nativa era estadunidense, tinha 16 anos e havia chegado ao Brasil quatro meses antes da gravação para a pesquisa. Todos foram 
gravados em estúdio com isolamento acústico, fazendo a leitura da frase veículo Say X, please, que continha as palavras alvo e também distratores. Foram selecionadas 12 palavras alvo (pop/poppy, Bob/Bobby, pet/petty, dad/daddy, luck/lucky, bug/buggy) e 24 distratores, totalizando 36 frases dispostas em ordem aleatória em três cadernetas distintas. Portanto, cada informante gravou três vezes o mesmo dado. Para a análise acústica, foi utilizado o programa gratuito Praat e referências como Kent \& Read (1992) e Ladefoged (1996) para a interpretação dos eventos acústicos.

\subsection{Resultados}

Primeiramente, o que se constatou em relação à produção dos vocábulos de sequência CVC foi a baixa taxa de ocorrência da epêntese - 7,4\% dos casos (16/216). Baptista \& Silva Filho (1997) obtiveram taxa de 15,2\% de ocorrência da epêntese, enquanto Koerich (2002) verificou a presença da vogal epentética em 44,45\% dos dados. O resultado de Ferreira (2007) veio a corroborar a correlação entre o frequente acréscimo da vogal em palavras que terminam em oclusivas e baixos níveis de proficiência na língua inglesa. Na grande maioria, a presença da vogal foi constatada após consoantes vozeadas, como mostra a tabela a seguir:

\begin{tabular}{|l|c|c|c|c|c|c|}
\hline & {$[\mathrm{p}]$} & {$[\mathrm{b}]$} & {$[\mathrm{t}]$} & {$[\mathrm{d}]$} & {$[\mathrm{k}]$} & {$[\mathrm{g}]$} \\
\hline Ocorrência & 1 & 6 & 0 & 1 & 3 & 5 \\
\hline Porcentagem & $6,25 \%$ & $37,5 \%$ & $0 \%$ & $6,25 \%$ & $18,75 \%$ & $31,25 \%$ \\
\hline
\end{tabular}

Estes números mostram a maior ocorrência da epêntese após as oclusivas bilabial e velar vozeadas e a pequena ocorrência da vogal após as alveolares, pois estas sofrem outros processos fônicos tratados mais adiante.

Com relação às características acústicas da vogal epentética, foi possível constatar com precisão a duração das mesmas, e em alguns casos identificar os formantes que indicam o tipo da vogal em questão. A duração de segmentos como vogais, por exemplo, não traz muita informação por si só, pois sofre variação por conta de vários fatores como características individuais e velocidade de fala. Contudo, foram feitas comparações entre as durações das vogais epentéticas 
produzidas por diferentes informantes para verificar se há alguma regularidade nesta questão, e também contrastes entre a duração da vogal epentética e da vogal final das palavras de sequência CVCV. Os resultados foram os seguintes:

1. As vogais epentéticas tiveram duração entre 27 e 78 milissegundos. A única relação feita para explicar tal distinção foi a de que se há uma fricção mais alongada após a articulação da consoante, como é o caso da consoante velar desvozeada, a duração da vogal é menor,

2. Na maioria dos casos, os formantes (ou pelo menos seus vestígios) apontaram para a produção da vogal anterior alta,

3. Em alguns casos, a vibração das pregas vocais continua após o término da articulação da vogal epentética.

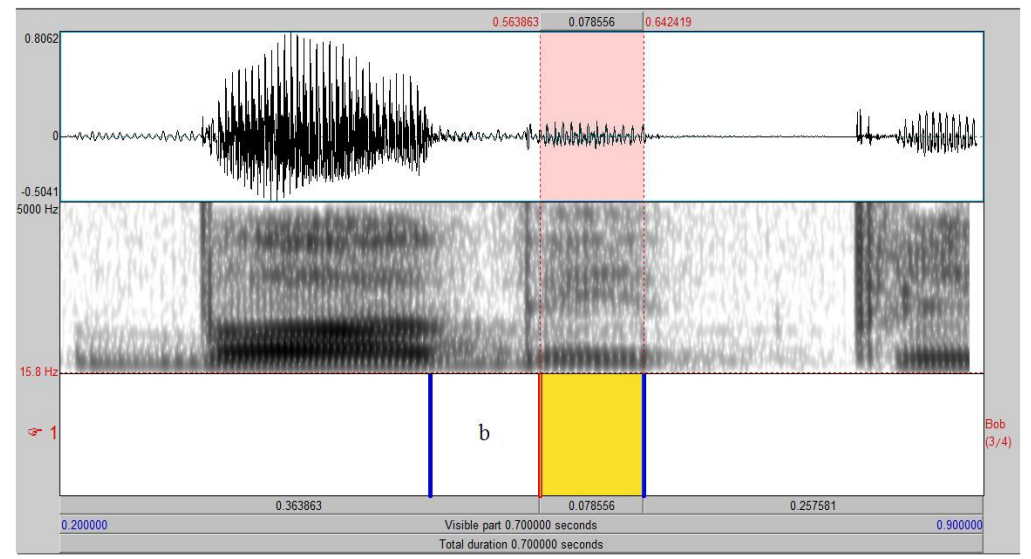

Figura 1: vogal acrescida a Bob

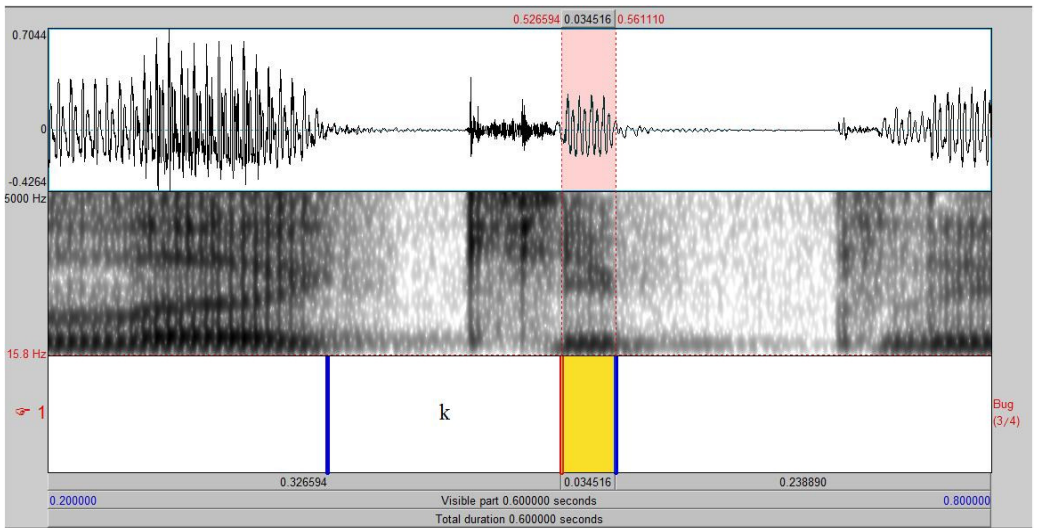

Figura 2: vogal acrescida a luck 
Pode-se observar a produção da vogal epentética em ambos os espectrogramas das figuras entre outras semelhanças. Nos dois casos é visível a barra de sonoridade, que indica o vozeamento, e os formantes, que trazem informações sobre a identidade da vogal (valores aproximados dos formantes da vogal anterior alta [i]). Já as principais diferenças entre as duas figuras são a duração das vogais em questão (78 e 34 milissegundos respectivamente), e a intensidade da produção (amplitude das ondas) entre os dois segmentos.

Durante a análise dos dados, foram comparadas as vogais finais dos vocábulos CVC que apresentavam a epêntese com as das palavras CVCV. Não houve uma grande regularidade na comparação entre os dados, mas em alguns casos, a vogal epentética era bastante semelhante à vogal final da palavra de sequência CVCV, como nos mostram as figuras a seguir:

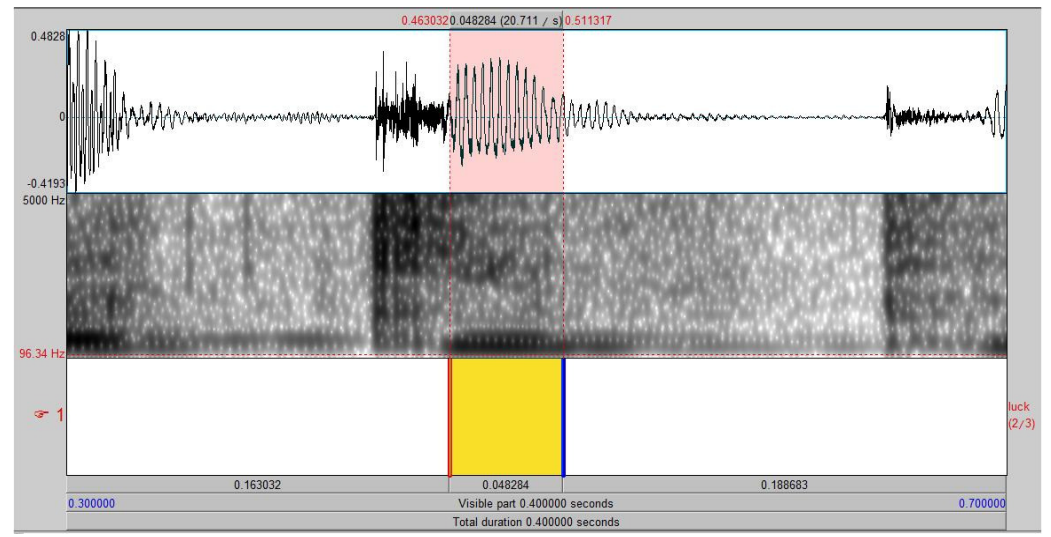

Figura 3: a palavra luck com a vogal epentética

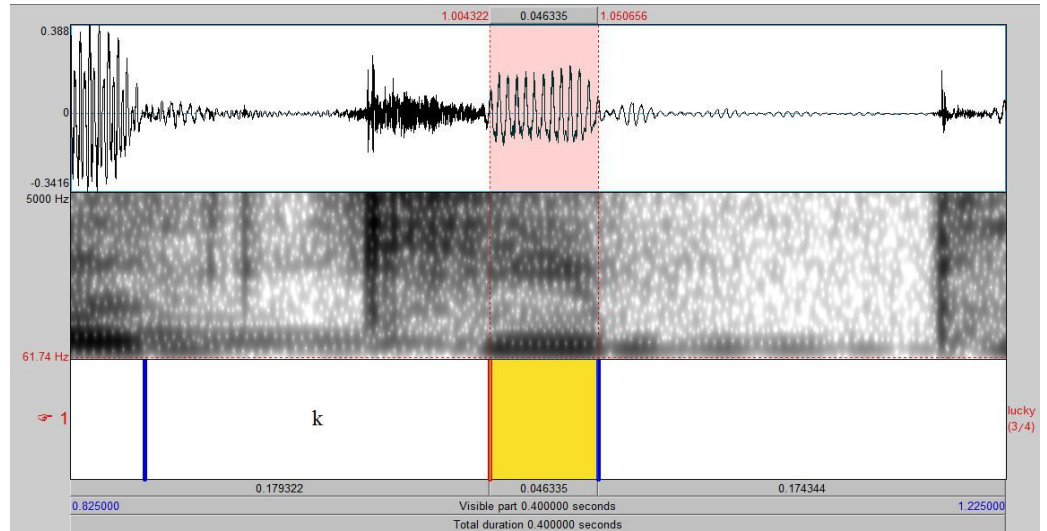

Figura 4: a palavra lucky

Vê-se nas figuras 3 e 4 que a mesma informante produziu as vogais finais praticamente da mesma forma: os dois segmentos tem quase a mesma duração (48 e 46 milissegundos), podem ser 
caracterizados como a vogal anterior alta, e apresentam barra vozeamento alongada. A grande diferença está na produção da consoante oclusiva que precede as vogais: há um ruído bem mais longo referente à fricção produzida pelos articuladores na produção da palavra lucky.

Através dos mesmos dados, também foi constatado que entre a produção dos vocábulos CVC na forma-alvo (com base nos dados da falante nativa) e os casos em que a vogal epentética foi empregada, há outros eventos fonéticos que acontecem de maneira bastante regular. Dentre esses processos fônicos estão a aspiração e a palatalização das consoantes finais, bem como o que se chamou de africação - o acréscimo de uma fricativa após as oclusivas alveolares. Este último evento foi o mais comum entre todos: dos casos em que os vocábulos foram produzidos com algum desvio da forma alvo, 37\% apresentavam a africação da oclusiva. A figura a seguir ilustra este processo fônico:

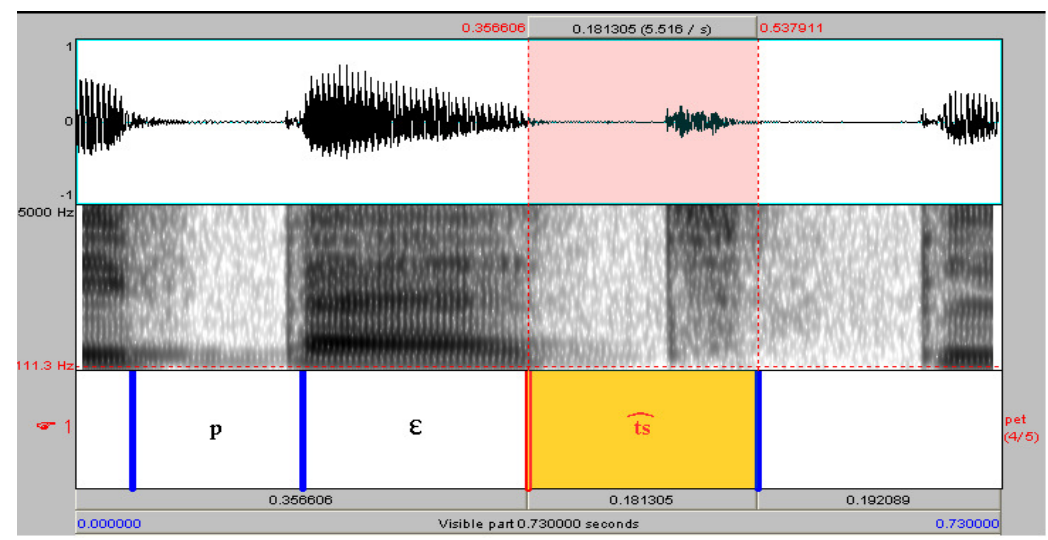

Figura 5: a produção da palavra pet por uma aprendiz brasileira.

Nesta figura é possível constatar que, depois da soltura dos articuladores na produção da oclusiva alveolar, a informante produz uma fricção bastante alongada, com características acústicas de uma fricativa alveolar surda. Este evento não poderia ser considerado somente um ruído provocado pela soltura dos articuladores por conta da sua duração ${ }^{2}$. Além disso, não há a possibilidade de interpretar tal segmento como [tsh], pois segundo Kent \& Read (1992), as fricativas alveolares tem concentração de energia significativa a partir de $4 \mathrm{KHz}$ (porção mais escura na camada do espectrograma), sendo que a fricativa palatal tem pico de energia a partir de $3 \mathrm{KHz}$ 
O segundo processo fônico com maior recorrência foi a aspiração, ocorrendo principalmente após as oclusivas velares desvozeadas. Em alguns casos, a aspiração veio acompanhada de um esboço de produção de uma vogal, como mostra a figura a seguir:

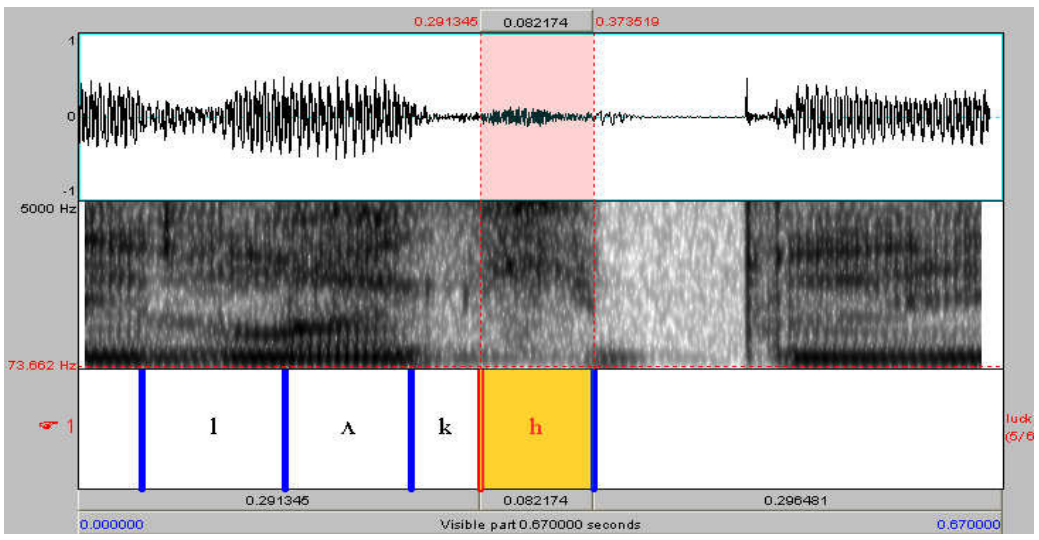

Figura 6: a produção da palavra luck por um informante brasileiro.

Nota-se nesta figura o informante produziu uma longa aspiração depois da oclusiva velar desvozeada, e que logo após este evento, produz a vibração das cordas vocais representada pela barra de sonoridade (porção escura no inferior do espectrograma logo após o término da aspiração). Isso indica que quase houve a produção de uma vogal por conta da queda na concentração de energia ao final da aspiração para uma frequência semelhante ao F2 de uma vogal anterior alta $(2 \mathrm{KHz})$.

\section{Conclusão}

No caso das nasais em final de sílabas, é fácil verificar que os brasileiros tendem a usar um processo que é obrigatório em Português: o traço nasal é simplesmente antecipado, sendo então co-articulado com a vogal (a ortografia distingue entre TAM e LÃ, mas os sons depois do ataque são, na verdade, idênticos). Há uma restrição em português que não permite qualquer consoante em coda, exceto /r/ e /s,z/, tal que essas consoantes ou são deletadas (como frequentemente ocorre em fala informal com o final /r/ de verbos no infinitivo), ou um traço é deletado e outro é antecipado (como ocorre com /1/ - o traço lateral é perdido enquanto o traço [+ recuado] é retido, resultando num ditongo em palavras tais como gol e mel - e as nasais, como nos exemplos vistos acima. O que é retido é o que se apresenta como mais necessário para que a comunicação seja bem sucedida, o traço mais contrastivo. No caso de obstruintes (excluindo o /s/, 
que frequentemente parece se encaixar fonologicamente nos padrões usuais de divisão silábica), não ocorre processo de redução ou apagamento, já que obstruintes não ocorrem em final de palavra em português. Obstruintes apenas ocorrem em português no ataque (com poucas exceções em posição medial, para alguns falantes). Por exemplo, o nome inglês Mike é usualmente pronunciado como dissílabo (rimando com Spiky), quando ocorre em um contexto de língua portuguesa. Até mesmo as nasais podem ser retidas e sofrer ressilabificação se o resultado do apagamento for uma palavra cujo som cause estranhamento - Wayne (como em Wayne Rooney) é usualmente pronunciada por comentaristas de futebol brasileiros como se rimasse com rainy. No caso de alguns empréstimos bem conhecidos, a grafia oficializou o processo: futebol, clube, basquete. Restrições fonotáticas do português em relação a possibilidades de coda parecem determinar qual estratégia é geralmente empregada para lidar com as codas do inglês nos estágios iniciais de aprendizagem. O que decorre então, como processos de aprendizagem, são tentativas de produção de codas próximas às normas da segunda língua, mas isso ocorre em etapas, conforme as pesquisas de Becker e Ferreira mostram. Para Silva (2008) é uma questão de gradualmente alterar as configurações gestuais. Em outras palavras, a Teoria da Otimalidade propicia uma boa explicação inicial, mas a fonética articulatória (BYBEE, 2001, Chapter 4) explica melhor a continuação da estória, uma vez que os aprendizes tentam modificar seus modelos articulatórios iniciais.

\footnotetext{
1 Anti-formantes, ou anti-ressonâncias, são as frequiências nas quais a cavidade da boca curto-circuita a transmissão através do nariz, quando da produção de uma consoante nasal (a cavidade oral está fechada em algum ponto) ( Kent \& Read, 1992, p. 37-38)

Kent \& Read (1992) afirmam que o ruído produzido na soltura da oclusão não dura mais do que 40 ms e é muitas vezes mais breve que isso. Neste caso, a porção fricativa da figura tem duração de aproximadamente $76 \mathrm{~ms}$.
}

\section{Referências}

BAPTISTA, B. O., \& SILVA FILHO, J.L.A. The influence of voicing and sonority relationships on the production of English final consonants. In: BAPTISTA, B. O. \& WATKINS, M. A. (eds). English with a Latin Beat: Studies in Portuguese/Spanish - English Interphonology. Amsterdam: John Benjamins, 2006, p. 73-90. 
BECKER, M. R. Análise Acústica da Produção de Nasais Bilabiais e Alveolares em Codas de Monossílabos por Alunos de Inglês. 2007. 96 f. Dissertação não publicada (Mestrado em Letras Estudos Linguísticos). Universidade Federal do Paraná. Curitiba, 2007.

BYBEE, J. Phonology and Language Use. Cambridge: CUP, 2001.

ECKMAN, F. R. From phonemic differences to constraint rankings: Research on second language phonology. Studies in Second Language Acquisition, 26. 2004, p. 513-549.

FERREIRA, A.P.P. Pet or Petty? Diferenças entre Palavras CVC e CVCV do Inglês por Aprendizes Brasileiros: Uma Análise Acústica. 2007. 138 f. Dissertação não publicada (Mestrado em Letras - Estudos Lingísticos). Universidade Federal do Paraná. Curitiba, 2007.

FUJIMURA, O. Analysis of Nasal Consonants. Journal of the Acoustical Society of America, v. 34, n. 12, 1865-1875, dez. 1962.

KENT, R.D.; READ, C. The Acoustic Analysis of Speech. San Diego : Singular Publishing Group, 1992. 238p.

KLUGE, D. Perception and Production of English Syllable-Final Nasals by Brazilian Learners. 2004. 77 f. Dissertação não publicada (Mestrado em Inglês e Literatura Correspondente), Universidade Federal de Santa Catarina. Florianópolis, 2004.

KOERICH, R. D. Perception and production of Vowel Epenthesis in Word-Final Single Consonant Codas. 2002. Tese de Doutorado não publicada. Universidade Federal de Santa Catarina. Florianópolis, 2002.

LADEFOGED, P. Elements of Acoustic Phonetics. 2.ed. Chicago: The University of Chicago Press, 1996. 
LADEFOGED, P. Vowels and Consonants: An Introduction to the Sounds of Languages. Malden, MA: Blackwell, 2001.

MAJOR, R. C. Paragoge and degree of foreign accent in Brazilian English. Second Language Research, 1986, p. 53-71.

MONAHAN, P. Evidence of transference and emergence in the interlanguage. Disponível em: $<$ http://roa.rutgers.edu/files/444-0701/444-0701-MONAHAN-0-0.PDF>. Acesso em: 25 nov. 2010, 10:33:09.

SILVA, A. H. P. Towards a dynamic view towards L2 phonological acquisition. In: RAUBER, A.S., WATKINS, M.A., \& BAPTISTA, B.O. (Eds.) New Sounds 2007: Proceedings of the Fifth International Symposium on the Acquisition of Second Language Speech. Florianópolis, Universidade Federal de Santa Catarina. 2008, p. 446-458.

SILVEIRA, R. The influence of pronunciation instruction on the perception and production of English word-final consonants. 2004. Tese de Doutorado não publicada. Universidade Federal de Santa Catarina. Florianópolis, 2004. 